\title{
Association between diabetes, obesity, aging, and cancer: review of recent literature
}

\author{
Judy K. Qiang ${ }^{1}$, Lorraine L. Lipscombe ${ }^{1,2,3,4}$, Iliana C. Lega ${ }^{1,2,3}$ \\ ${ }^{1}$ Department of Medicine, Division of Endocrinology and Metabolism, University of Toronto, Toronto, Ontario, Canada; ${ }^{2}$ ICES, Toronto, Ontario, \\ Canada; ${ }^{3}$ Women's College Research Institute, Women's College Hospital, Toronto, Ontario, Canada; ${ }^{4}$ Institute of Health Policy, Management and \\ Evaluation, University of Toronto, Toronto, Ontario, Canada \\ Contributions: (I) Conception and design: All authors; (II) Administrative support: None; (III) Provision of study materials or patients: None; (IV) \\ Collection and assembly of data: None; (V) Data analysis and interpretation: None; (VI) Manuscript writing: All authors; (VII) Final approval of \\ manuscript: All authors. \\ Correspondence to: Dr. Lorraine L. Lipscombe. Women's College Hospital, 76 Grenville Street, 3rd Floor, Room 6424, Toronto, ON M5S 1B2, \\ Canada. Email: Lorraine.Lipscombe@wchospital.ca.
}

\begin{abstract}
Rates of obesity and diabetes have risen significantly in recent years and are projected to increase even further in the coming decades. Obesity and diabetes are associated with increased risk of certain tumours, with the strongest relationships demonstrated for colorectal, post-menopausal breast, and endometrial cancer. Another important risk factor for cancer development is aging. Aging is characterized by chronic inflammation and immunosenescence, and accelerated by obesity, which may further stimulate the development of cancer. In this review, we summarize recent literature on the complex interactions between obesity, diabetes, aging, and cancer risk and mortality. We will also provide an overview of both epidemiological as well as pathophysiologic data and their clinical implications. In the context of an aging population and anticipated rise in rates of obesity and diabetes, a better understanding of how these factors interact and impact on cancer risk and prognosis will be important in helping to guide therapeutic interventions.
\end{abstract}

Keywords: Cancer; diabetes mellitus; obesity; aging

Submitted Feb 11, 2020. Accepted for publication Feb 27, 2020.

doi: $10.21037 /$ tcr.2020.03.14

View this article at: http://dx.doi.org/10.21037/tcr.2020.03.14

\section{Introduction}

Obesity and diabetes have become a global epidemic. A significant proportion of people are diagnosed with diabetes in both developing and developed countries (1,2). In 2015, approximately 30 million American adults had diabetes, representing nearly $10 \%$ of the entire U.S. population, with most of the patients diagnosed with type 2 diabetes (3). Data from the National Health and Nutrition Examination Survey (NHANES) show that rates of obesity in the U.S. have increased dramatically since the 1960s, with prevalence of obesity of $35 \%$ in 2012, and globally representing nearly 2 billion adults $(4,5)$. Rates of obesity are expected to increase over the next 20 years (6), and more than $80 \%$ of adults will be either overweight or obese by the year 2048 (7). Given that obesity is a major risk factor for diabetes, it is not surprising that the rates of types 2 diabetes have also increased, closely mirroring those of obesity. Although type 2 diabetes is traditionally regarded as an adult onset condition, there is increasing prevalence among children and adolescents (8), largely attributed to increased rates of obesity early in life (9).

Diabetes is associated with an increased risk of several cancers, particularly malignancies of the colorectum, endometrium, and breast (10-16). Furthermore, diabetes may also affect cancer prognosis and overall mortality (17-21). The relationship between cancer and diabetes is complex, with shared risk factors such as pro- 


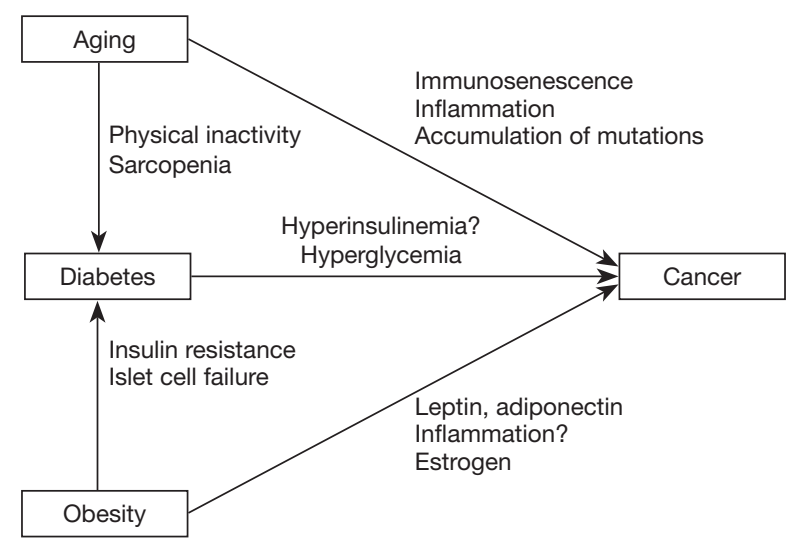

Figure 1 Interactions between aging, diabetes, obesity, and cancer. Obesity and advanced age are two risk factors for diabetes. Aging contributes to the development of diabetes due to physical inactivity, sarcopenia, which can cause insulin resistance and diabetes. In obesity, insulin resistance initially leads to hyperinsulinemia. Overtime, the pancreas is unable to continue to secrete sufficient insulin and decompensation occurs, leading to diabetes. Aging, diabetes, and obesity all contribute to carcinogenesis.

inflammatory effects of excess adipose tissue (22-24). Additionally, hyperinsulinemia and insulin resistance, as well as hyperglycemia have been proposed as independent mechanisms linking diabetes with increased risk of malignancies (25).

Another important risk factor for cancer is age. Aging is characterized by an accumulation of genetic alterations. It is also a state of chronic inflammation and a decline in immunity (26), which may be accelerated by obesity (27). Age related changes in the immune system are associated with multiple pathological processes underlying malignancy development (28) (Figure 1).

In this review, we will summarize recent evidence for the associations between diabetes, obesity, aging, and cancer. We performed a PubMed search, restricting to English language publications in November 2019 using these search terms: "Neoplasm or Cancer", "Obesity", "Diabetes" AND "Aging". Reference papers were individually reviewed by the authors.

\section{Obesity and cancer}

\section{Obesity is associated with increased risk of cancer}

Overweight is defined as body mass index (BMI) of 25.0 to $29.9 \mathrm{~kg} / \mathrm{m}^{2}$ whereas obesity is defined as BMI of $\geq 30 \mathrm{~kg} / \mathrm{m}^{2}$. While non-obesity related cancers have decreased in the $21^{\text {st }}$ century, obesity related cancers have increased (29). Obesity is an independent risk factor for 13 types of cancer, shown by the International Agency for Research on Cancer
(IARC) (30). Examples include endometrial, postmenopausal breast, renal cell, colorectal, gastrointestinal, and pancreatic cancer (31-34). A prospective study showed that in 2014, obesity related cancers accounted for $40 \%$ of all cancers (35), and these malignancies are more commonly observed among women than men, older individuals (age $>50$ ), and non-Hispanic African Americans (35,36). Multiple studies across different populations have found that women are disproportionally affected by obesity related cancers, with some studies showing that the population attributable fraction of cancer for women is approximately twice as high as men $(37,38)$. This difference likely reflects the strong association between obesity and female cancers including endometrial, ovarian, and breast cancer.

Certain cancers show stronger associations with obesity than other cancer types-colorectal cancer (relative risk, RR 1.3-1.4), postmenopausal breast cancer (RR 1.1-1.2), and endometrial cancer (RR 6.3-8.1) (30). Obesity is correlated with increased risk for different subtypes of postmenopausal breast cancer including both estrogen receptor (ER) and progesterone receptor (PR) positive breast cancer (39-42) as well as triple negative breast tumours (43). While obesity is a strong risk factor for postmenopausal breast cancer $(44,45)$, increased weight early in life may confer a lower risk of premenopausal breast cancer (46-48). Previous studies including a large study which included over 750,000 premenopausal women found that younger women with higher BMI had a lower risk of premenopausal breast cancer compared to those with lower BMI $(49,50)$. However, it is unclear whether this 
association is seen across all ethnicities. For example, an older systematic review found that obesity was correlated with increased risk of both pre and postmenopausal breast cancer in women of Asian descent (51). However, this was not replicated by other studies. Future studies are required to elucidate the mechanisms by which obesity may confer a protective effect against breast cancer development among younger, pre-menopausal women and to better understand the effect of obesity on risk of breast cancer development amongst different ethnic groups.

Interestingly, in prostate cancer, the relationship between obesity and cancer risk is less clear. One study found that a high BMI may correspond to a lower risk of cancer but an elevated waist circumference may correlate with a higher risk (52), whereas a pooled analysis found a higher BMI was associated with increased risk for advanced prostate cancer (53). These discordant findings may reflect methodological variations and differences in study populations. However, they may also highlight the limitations of using BMI as a surrogate marker for adipose tissue given that it does not differentiate muscle from fat mass, nor site of adiposity. Furthermore, some authors have demonstrated that waist circumference, which provides a better estimate of visceral adiposity than BMI may be more indicative of prostate cancer risk than BMI alone (54-56).

\section{Possible mechanisms linking obesity and cancer}

Multiple hypotheses have been proposed as possible mechanisms linking obesity with development of cancer. First, obesity is linked to a state of chronic inflammation $(57,58)$. Pro-inflammatory cytokines may enhance tumour cell proliferation, angiogenesis, and invasion into healthy cells, metastasizing into distant organs (59). In breast cancer, for instance, higher levels of cytokines such as tumour necrosis factor (TNF-alpha) and interleukin (IL-6) among obese patients are positively correlated with progression of tumour (60). In addition, epidemiological data show that rates of cancer are increased among patients with chronic inflammatory conditions, leading to the hypothesis that inflammation may contribute to neoplasm development (61).

Second, adipokines such as adiponectin and leptin, which are hormones derived from adipose tissue may play an important role in cancer formation. Adiponectin regulates glucose metabolism and fatty acid oxidation, and it is inversely correlated with BMI. In vitro models have shown that adiponectin may have protective effects against carcinogenesis in breast, endometrial, colon, and prostate cancer (62-65). Leptin is mostly produced by adipocytes to induce satiety and reduce hunger. Leptin deficiency is a rare cause of severe obesity, which typically arises in childhood (66). More commonly, leptin levels are higher in individuals with obesity compared to normal weight individuals. Individuals with obesity exhibit leptin resistance, similar to insulin resistance in type 2 diabetes (67). Higher leptin levels are associated with increased cancer risk (68). Pre-clinical studies have shown that leptin is involved in inflammatory, mitogenic and pro-angiogenic pathways in breast cancer development (69). One study found that inhibition of leptin signaling reduced the growth of carcinogen-induced breast cancer (70).

Third, high adiposity is associated with increased serum estrogen, as estrogen production is increased through peripheral aromatization of androgens via aromatase activity in adipose tissues. Excess estrogen can promote tumour development through DNA damage, angiogenesis, and cellular proliferation $(71,72)$. There are ERs on certain obesity related tumours such as breast and endometrial cancer. This may explain the finding that postmenopausal women with a higher BMI have been shown to have an increased risk of ER and PR positive breast cancer (44). An analysis of eight prospective studies showed that the risk for postmenopausal hormone positive breast cancer is at least partially attributable to increased estradiol levels (73). On the other hand, the protective effect of earlier onset obesity on pre-menopausal breast cancer development is not well understood but the inverse relationship between obesity and pre-menopausal breast cancer risk is primarily seen with ER positive tumours rather than ER negative tumours, suggesting a hormonally mediated pathway. Previous studies have postulated that the estrogenic effect of obesity in adolescence may lead to higher levels of tumour suppression genes, therefore reducing the risk of breast cancer development. Furthermore, it has been speculated that high levels of estrogen due to aromatase action in fat tissue may shut off the hypothalamic/pituitary/ovarian axis, resulting in amenorrhea, which is a known protective factor against breast cancer formation (49). However, this has not been a consistent finding in the literature, therefore further studies are required to further characterize the relationship between timing of obesity onset and breast cancer risk. 


\section{Obesity may confer worse cancer prognosis and increase treatment related complications}

Obesity may be a negative prognostic factor for cancer recurrence and survival for a variety of cancer types. It is estimated that each 5\% increase in BMI is associated with a $10 \%$ increase in cancer related deaths (74). Higher BMI has been shown to increase the risk of rectal cancer and breast cancer recurrence $(75,76)$, and worse survival in pancreatic $(77,78)$ and colon cancer $(79,80)$. Death from multiple myeloma is $50 \%$ more likely for obese individuals as compared to lean individuals (81). A recent meta-analysis including 82 studies involving over 200,000 breast cancer patients found that overall and cancer specific mortality was increased among women with obesity with a relative risk of 1.41 (95\% CI, 1.29 to 1.53 ) and 1.35 (95\% CI, 1.24 to 1.47 ), respectively, compared to women with normal weight (82). Several studies have shown that obese patients present with larger breast tumours, with a subset of studies showing that breast cancer may be more advanced at the time of presentation $(83,84)$. This may be partially due to lower cancer screening among women with obesity $(85,86)$, lower detection of smaller tumours, and barriers in accessing screening and appropriate follow up secondary to obesity associated stigma and competing care demands (87). In addition, breast tumours in women with obesity may be more biologically aggressive, resulting in higher risk of recurrence and mortality, with the strongest evidence shown for ER+ cancer (88-90). Furthermore, endocrine or chemotherapy may be less effective in obese patients compared to patients with normal weight, despite appropriate doses of chemotherapy (91), possibly through JAK2/STAT3 mediated chemoresistance (92).

Obesity has also been found to be associated with an increased risk for treatment-related complications. In breast cancer, for instance, obese patients are at higher risk for anesthesia related complications and are more likely to experience respiratory difficulty in the perioperative setting (93). Rates of lymphedema are also higher in breast cancer survivors $(94,95)$. In a multicenter Italian study, obesity was associated with a higher risk of incontinence in prostate cancer survivors treated with radical prostatectomy (96). A population-based Dutch study of patients with colorectal cancer undergoing surgery showed that obesity was a major determinant for post-operative complications, increased length of stay, and greater readmission risk (97).

\section{Impact of weight loss on cancer risk and mortality}

Weight loss may be associated with a decreased risk of the developing obesity related cancers. The Iowa Women's Health Study showed that women with 20 pound or more weight loss had a $14 \%$ reduction in risk of obesity related cancers, including breast, colon, and endometrial cancers (98). Similarly, in the Women's Health Initiative cohort, weight loss among women with obesity was associated with a $54 \%$ lower risk of endometrial cancer (99). A recent large, prospective U.S. cohort study, which consisted of over 58000 post-menopausal women aged 50-79 years, found a significant reduction in incidence of obesity related cancers among women who intentionally lost $5 \%$ or more of their body weight during a 3 -year study period (100). Weight loss achieved through bariatric surgery has also been shown to be associated with an approximately $40 \%$ reduction in obesity related cancers after 3.5 years of follow up (101). It is important to keep in mind that it is possible some of the reduced cancer risk may be due to lifestyle optimization and changes in behavioural factors, such as diet and physical activity $(102,103)$, rather than weight loss itself. Nonetheless, these findings are encouraging and suggest that even a relatively modest weight loss may be beneficial for cancer risk reduction. Given that few studies have systematically examined the effect of weight loss on cancer risk in men, future efforts to study this population would be helpful.

Existing literature on the effect of weight loss on cancer outcomes is sparse; most of the data come from the breast cancer literature. For example, the Women's Intervention Nutrition Study randomized 2,437 women with stage I to III breast cancer to either standard care or a low-fat diet. The intervention group lost a mean of 6 pounds in body weight, and after a period of 5.6 years, disease-free survival was higher in the intervention group as compared to the standard care group (hazard ratio $0.76,95 \% \mathrm{CI}$, 0.60 to 0.98$)$ (104). However, these findings lost statistical significance during follow up, possibly due to decreased diet adherence during this period (105). The more recent SUCCESS-C trial randomized women with stage II and III breast cancer first to one of two chemotherapy treatments, then assigned those with BMI 24 to $40 \mathrm{~kg} / \mathrm{m}^{2}$ to either a weight loss intervention or standard care (106). Interim analysis showed that participants in the weight loss group had a mean weight loss of $1 \mathrm{~kg}$ while the control group gained an average of $0.95 \mathrm{~kg}$ over the study period. While 
there was no difference for either disease-free or overall survival between the groups in intention-to-treat analyses, women who completed the weight loss intervention had better disease-free survival compared to those who left the intervention group (hazard ratio $0.35,95 \%$ CI, $0.27-0.45$ ). The high drop-out rate of more than $50 \%$ in the weight loss group compared to $20 \%$ in the control group makes these findings difficult to interpret. Large, well conducted studies are needed to provide definitive evidence for the impact of weight loss on survival following cancer. Such studies are underway for breast cancer $(106,107)$, and are needed for other obesity related cancers.

\section{Diabetes and cancer}

\section{Diabetes and cancer risk}

Earlier epidemiologic studies showed that type 2 diabetes may be associated with an increased risk of pancreatic cancer, colorectal cancer, breast cancer, and cholangiocarcinoma (108-111). However, these early observational studies did not properly adjust for confounders and were prone to detection bias and protopathic bias and may have overestimated initial risk estimates (10). More recent epidemiologic studies in this area have used statistical methods to minimize these biases $(112,113)$. A recent, large meta-analysis found consistent associations between diabetes and increased risk for certain cancers such as malignancies of the colorectum (pooled RR of $1.27,95 \%$ CI, 1.21-1.34), breast (pooled RR of $1.20,95 \%$ CI, 1.12-1.28), and endometrium (pooled RR of $1.97,95 \%$ CI, 1.71 to 2.27 ) (16). A recent European cohort study found that diabetes correlated with increased risk of gastrointestinal cancers even after applying a 1 -year lag period to adjust for detection bias (114). The association between diabetes and increased risk of renal, pancreatic, hepatocellular, gastric, and thyroid cancers is more uncertain due to methodological limitations and heterogeneity of previous studies.

There is also evidence for an increased cancer risk even prior to the diagnosis of diabetes, a period that is marked by hyperinsulinemia and insulin resistance. A U.S. study found a $16 \%$ increased risk of breast cancer in the 10 years prior to onset of type 2 diabetes, and a $28 \%$ increased risk for colorectal cancer in men before diabetes diagnosis (115). Our group found that patients with diabetes had a $23 \%$ higher risk of being diagnosed with cancer in the 10 years prior to a clinical diagnosis of diabetes (116). These findings suggest a possible role for hyperinsulinemia in oncogenesis (to be discussed further in "Mechanisms linking diabetes and oncogenesis").

Interestingly, as with obesity, diabetes may be protective against prostate cancer. A meta-analysis found a $14 \%$ lower risk of prostate cancer among patients with diabetes $(117,118)$. Some of the postulated mechanisms for this inverse relationship include (I) lower circulating testosterone levels among patients with diabetes and therefore decreased stimulation of the prostate (119); (II) detection bias secondary to fewer diabetes men getting prostate biopsies, even with elevated PSA (120). While previous studies have also suggested that anti-diabetic medications may have a protective effect against the development of prostate cancer (121), this was not supported by a recent large European population based study (120).

Given that obesity is frequently associated with type 2 diabetes, it important to isolate the effect of diabetes on cancer risk apart from that of obesity. It has been shown that obese woman with diabetes have a higher risk of endometrial cancer than those with diabetes alone (122). In a large meta-analysis, Pearson-Stuttard et al. estimated the global cancer burden attributable to diabetes alone versus diabetes and obesity combined, and found that in 2012, $6 \%$ of all incident cancers were attributable to the combined effects of diabetes and obesity. Obesity alone (3.9\% of all new cancer cases) was responsible for almost twice as many cases of cancer as diabetes ( $2.1 \%$ of all new cancer cases) globally (123), indicating that obesity may be the more important contributory factor than diabetes in its impact on cancer incidence.

There are fewer studies that have examined the association between type 1 diabetes and cancer risk. A large European population based study showed a slightly higher risk of cancer among female patients with type 1 diabetes, with a hazard ratio of 1.07 (95\% CI, 1.04, 1.10) among women and 1.01 (95\% CI, 0.98, 1.04) among men (124). The increased risk was seen for gastric, liver, pancreas, endometrium and kidney tumours, and a reduced risk for prostate and breast cancer. Interestingly, risk of cancer was highest around the time of diabetes diagnosis, which suggests a possible role for detection bias in this association. Another more recent meta-analysis of 15 observational studies and 13 cohort studies found the same decreased risk of breast cancer among patients with type 1 diabetes (125). Overall, the mechanism for this possible association remains unclear. Future studies are required to further elucidate the relationship between type 1 diabetes and breast cancer. 


\section{Mechanisms linking diabetes and oncogenesis}

The pathophysiology of type 2 diabetes involves development of hyperinsulinemia in response to insulin resistance, which eventually results in hyperglycemia (126). Over time pancreatic beta cells undergo apoptosis, leading to decreased beta cell mass and clinical manifestations of type 2 diabetes. Prospective studies have shown that hyperinsulinemia may occur as early as 18 years prior to the diagnosis of diabetes (127).

It is well established that hyperinsulinemia is associated with higher risk of breast, colorectal, and endometrial cancer $(128,129)$. Insulin may lead to oncogenesis via several mechanisms. Insulin exerts its effect through the action of IGF1 and IGF2, which have critical roles in cell survival and proliferation. IGF1 is expressed in prostate tumours and promotes androgen responsive prostate cancer growth (130), even in a growth hormone suppressed state. IGF-1 receptor plays an important role in the pathogenesis of multiple myeloma through its effect on the receptor tyrosine kinase FLT3 (131) and the fusion oncoprotein MLL-AF9 (132), which contributes to the malignant transformation of hematopoietic progenitor cells. IGF-1 levels are higher among patients with more advanced CRC compared to those with less advanced CRC (133). An invitro study demonstrated that activation of IGF-1/STAT3 signaling increased colorectal cancer formation and that inhibition of this pathway reduced tumour burden (134). Higher IGF-1 levels may indicate higher risk for recurrence in breast cancer (135). In addition to IGF-1 mediated pathways that may contribute to carcinogenesis, IGF-2 can also promote tumour development through insulin receptor (IR-A). Novosyadlyy et al. (136). observed the acceleration of breast cancer development through IR mediated pathways that could be reversed by inhibition of IR signaling in mice. Similarly, Lu et al. showed proliferation of CRC cells via IR signaling and downstream increase in PI3K/Akt and MAPK activation (137).

It is unclear whether hyperglycemia by itself is an independent contributor to cancer growth or whether it exerts indirect effects through hyperinsulinemia, IGF, IR, and inflammatory cytokines. It has long been postulated that cancer cells have increased glucose uptake and uses glucose as fuel for proliferation due to damaged mitochondria in cancer cells, known as the Warburg effect $(138,139)$. Poor glycemic control has been shown to increase levels of advanced glycation end products (AGE) which activate receptors to bind inflammatory cytokines that are involved in oncogenesis (140). In a large systematic review of 35 studies, $\mathrm{Xu}$ et al. (141) found that HOMA-IR, which is a measure of insulin resistance, was a better predictor of CRC risk than fasting glucose and fasting insulin. However, markers of long-term glycemic control such as glycated hemoglobin (A1c) also correlated with CRC risk, albeit this was a weaker predictor of cancer risk. Given this study included mostly case-control studies, future prospective studies are required to better understand the effect of glycemic control as an independent risk factor for cancer development. In contrast, a recent population-based cohort study showed that overall, A1c had no association with risk of certain cancers such as malignancies of the colorectum, breast, lung, and liver (HR 1.0, 95\% CI, 0.98-1.02 for all sites) (142). In summary, it is difficult to disentangle the individual effect of glycemic control from other aspects of metabolic syndrome on cancer risk. Well designed, prospective studies are needed to definitively answer this question in the future.

\section{Diabetes and mortality}

Evidence indicates that patients with diabetes have higher mortality rates after cancer diagnosis. Many older studies did not adjust for stage at cancer diagnosis or take into account competing risks, and were not designed to separate overall mortality from cancer specific mortality. We have shown in CRC that comparing to patients without diabetes, those with diabetes had a modestly increased overall mortality (adjusted hazard ratio of 1.08, 95\% CI, 1.04, 1.12), but a similar CRC specific mortality (143). We did find a trend towards increased CRC-specific mortality among patients with diabetes of at least 2 years compared to those with recent onset diabetes. Similarly, a recent population based U.S. study among older adults (age $>67$ years) showed that there was a small increase in CRC-specific death among diabetes patients with diabetic complications (144). A large pooled analysis of 97 prospective studies showed that diabetes was associated with a moderately increased risk of cancer specific death from multiple cancers, including breast cancer (145). In addition, our group showed that, in patients with diabetes and breast cancer, cancer-specific mortality was increased only among those with longer diabetes duration and cardiovascular disease (21). These data indicate that chronicity of metabolic derangement and comorbidities may be important prognostic factors for cancer specific survival among individuals with diabetes.

In contrast, diabetes has consistently been shown to be 
associated with increased all-cause mortality after a cancer diagnosis, particularly for colorectal, breast, and endometrial cancers (18-20,146,147). For instance, Barone et al. (148) found that all-cause mortality was increased in diabetes patients with CRC (pooled HR of 1.32, 95\% CI, 1.24, 1.41), endometrial cancer (pooled HR of 1.76, 95\% CI, 1.342.31), and breast cancer (pooled HR of 1.61, 95\% CI, 1.461.78). Similarly, a more recent U.S. population based study showed that in older adults, pre-existing diabetes increased overall mortality among patients with CRC (HR 1.2, 95\% CI, 1.17, 1.23) (20). The discrepancy between cancerspecific and overall mortality has been largely attributed to increased risk of cardiovascular deaths in patients with diabetes $(20,149)$. These results indicate that optimization of non-cancer care is important in improving outcomes for patients with diabetes and cancer.

\section{Aging and cancer}

\section{Age is a risk factor for cancer development}

Age is a risk factor for both cancer and diabetes. A U.S. national survey in 2017 showed that among U.S. adults, the prevalence of diabetes was $2.9 \%$ among those aged 20-44 years, $12.4 \%$ among those aged $45-64$ years, and $19.8 \%$ among those older than 65 years of age (150). The incidence of diabetes in the U.S. in 2015 was 3.1 per 1,000 for age $18-44,10.9$ per 1,000 for age $45-64$, and 9.4 per 1,000 for those older than 65 years of age (151).

Risk of cancer also tends to increase with age. Recent population-based data from the U.S. Surveillance Epidemiology and End Results (SEER) database in 2015 indicated that the median age of cancer diagnosis was 66 years, with $25 \%$ incident cancer diagnosed among those between 65 to 74 years of age (152). The median age at diagnosis was 61, 68, 70, and 66 years for breast, colorectal, lung, and prostate cancer, respectively (152). Among cancers diagnosed during this period, 5.2\% were among those aged 35-44 years, $14.1 \%$ among those aged $45-54$ years, $24.1 \%$ among those 55-64 years, and $25.4 \%$ among those aged 65-74 years (152).

While rates of certain cancers have decreased overtime, the overall rates of new cancer cases rose between 1975 and 2015 in the U.S. (153) Cancer incidence is expected to rise in the coming decades. In 2015, the Canadian Cancer Society reported that the incidence of cancer is expected to rise by $40 \%$ over the next 15 years (154). One contributing factor is rising age. The median age of the Canadian population was 26.2 years in $1971,39.5$ years in 2009, which is projected to rise to between 42 and 45 years by 2036 . In 2036, about $25 \%$ of all Canadians will be seniors (age > 65 years) (155). Another contributing factor is the rising rates of obesity (4-7). Some of the most common types of cancer such as breast and colorectal cancer are obesity associated cancers (156). Not only do rising rates of obesity contribute to increased cancer rates, they also lead to increased rates of diabetes (4). Coupled with an aging population, higher rates of obesity and diabetes further add to the burden of cancer in the population.

\section{Mechanisms of carcinogenesis in the aging individual}

An accumulation of mutations is a major theory for mechanisms of aging and plays an important role in the pathogenesis of many malignancies (157). An increase in somatic mutations with age has been documented in a variety of target genes, such as T-cell receptor (158), using various techniques such as chromosome painting and single nucleotide polymorphism (SNP) arrays (159-162). An analysis of several genome-wide association studies (GWAS), which included more than 100,000 patients found that the presence of large leukemia-associated chromosomal abnormalities increased with age (161). Nair et al. demonstrated age related increase in driver mutations such as PIK3CA, KRAS, and PTEN in women with endometrial cancer (163). These genetic aberrations do not remain static, and are modulated by several environmental factors, such as smoking, infections, and toxin exposures overtime $(164,165)$.

Aging is associated with a chronic, low-level inflammation, known as "inflammaging" (26), which contributes to the development of cancer. Cytokine production in response to Toll-like receptor (TLR) activation is significantly increased with aging. Hearps et al. showed that aging is associated with a persistence in TLR activation following West Nile virus infection in monocytes from older individuals (166). In a cross-sectional study of over 800 patients, age 85 or older, Collerton et al. (157) found a positive correlation between inflammatory markers including IL-6, TNF-alpha, CRP and frailty, defined using Fried and Rockwood models, which are two commonly used measurements of frailty. It has also been shown that dendritic cell production of anti-inflammatory cytokines such as IL-12 and IL-10 is reduced among older individuals (167).

Inflammation and carcinogenesis are two interconnected 
processes. Inflammation may trigger genetic mutations or epigenetic changes, resulting in carcinogenesis (168). Inflammatory cells interact with tumour cells and surrounding stroma to create an immunosuppressive tumour microenvironment, allowing for cancer progression and metastasis $(162,169)$. A proinflammatory environment also leads to worse cancer prognosis in triple negative breast cancer (170), Hodgkin's lymphoma (171), and colorectal cancer (172). Aging is also associated with immunosenescence, a process characterized by a reduction in $\mathrm{B}$ and $\mathrm{T}$ cell proliferation and function, as well as loss of immune regulation, which plays a vital role in age related decline of antitumor immunity (157). Although inflammation is recognized as an important player in tumour formation and progression, a better understanding of the complex interactions between inflammation and immunity is required to improve current immunotherapy strategies and cancer-related outcomes.

\section{Worse cancer outcomes among older patients with cancer}

There is epidemiological evidence to suggest that older patients have worse net cancer survival compared to younger patients, even after adjusting for mortality from non-cancer causes (173). In men, the largest age gaps in survival was found for lymphoma, multiple myeloma, and leukemia. For women, the largest age gaps in survival was shown for brain cancer, ovarian, cervical cancer, and multiple myeloma. These age-related differences in survival likely reflects both biological factors as well as differences in healthcare use and delivery between older and younger patients. One of the most important determinants of survival is stage at diagnosis. For instance, it has been shown that individuals age 85 or older are more likely to present with later stage disease compared to those who are 65 to 84 years of age (174). Breast and colorectal cancer patients older than 85 years of age are $10 \%$ are more likely to present with more advanced cancer compared to adults between ages 65 to 84 (174). Taken together, these findings indicate that older adults may present with more advanced cancer at the time of diagnosis, which may lead to worse survival outcomes.

Selecting the appropriate cancer treatment in the older adult requires careful consideration, given the multiple medical comorbidities that many elderly patients face. Previous studies showed that older patients with breast cancer are less likely to receive evidence based medical care, even after adjusting for medical comorbidities $(175,176)$. Using the U.S. SEER database, LeMasters et al. found that patients older than 75 years of age were approximately $40 \%$ less likely to receive guideline-based care, suggesting possible under-treatment of cancer among the elderly (175). However, this may be clinically appropriate in an older, frail individual who may not be able to tolerate cancer treatment. In fact, the same authors found that the presence of certain concurrent chronic conditions such as diabetes and heart disease reduced the likelihood of receiving guideline-based care, due to physician concerns regarding increased risk of treatment complications $(176,177)$. While it is important not to over-treat this vulnerable population, it is equally important not to stereotype all older adults as frail, who will invariably deteriorate and lose their independence (178). Older adults are a heterogeneous population. Chronological age does not necessarily equal biological age, and may not reflect underlying immune function and degree of immunosenescence (179). Given that most clinical trials have traditionally excluded older adults from participating, there is a need for age-specific clinical studies to provide better evidence based clinical decision making tools to improve cancer care for older adults with cancer $(180,181)$.

\section{Aging in cancer survivors}

Cancer $(179,182)$ and cancer treatments may accelerate the aging process. Aging is characterized by a gradual accumulation of cellular damage leading to dysregulated organ function (183). Systemic cancer therapies and radiation accelerate aging by increasing inflammation (184), inducing immunosenescence $(185,186)$, causing DNA damage and decreasing telomere length (187-189). Examples of chemotherapies that promote aging include alkylating agents, such as cyclophosphamide, anthracyclines, such as doxorubicin, topoisomerase inhibitors, such as irinotecan, antimetabolites/cytotoxic drugs such as 5-FU (190).

Furthermore, some of these agents can also cause organ damage, as in the case of doxorubicin related cardiotoxicity, which further adds to frailty and the aging process among cancer survivors (190). Long term follow up studies of childhood cancer survivors show that these patients have higher rates of functional loss, frailty, medical comorbidities and cognitive decline, with much earlier onset than healthy controls (191-193). Specifically, adult survivors of childhood cancer were three times more likely to have a chronic condition, and 8 times more likely to have a severe condition and nearly all have at least one chronic medical condition by age $50(194,195)$. Recognition of these late effects have led to efforts to improve cancer treatments to 
reduce their associated toxicity. Follow up data from the Childhood Cancer Survivor Study cohort demonstrated that overall, the 20-year cumulative incidence of at least one significant chronic condition has decreased from $33 \%$ to $27 \%$ patients treated from 1970-1979 compared to 1990-1999 (196). Longitudinal studies to determine aging trajectories among childhood cancer survivors, and mechanistic studies to characterize the pathways that lead to accelerated aging are underway, and will help to inform strategies to optimize health of the aging cancer survivor.

A 2016 study (197) using SEER data found that among adult cancer survivors, the most common comorbid conditions were congestive heart failure (6-20\% depending on age of the survivor), chronic obstructive pulmonary disease (17-21\%) and diabetes (23-28\%). The distribution of comorbidities differed by cancer site such that patients with lung cancer had much higher rates of certain conditions such as CHF and COPD, likely reflecting tobacco use as a common risk factor for both lung cancer and cardiac and other respiratory comorbidities. Interestingly, there was no significant difference in the burden of comorbidities among individuals in the same age category when stratified by cancer status. For instance, $23 \%$ of adults without cancer aged $80-84$ years had diabetes whereas $27 \%$ of adults with cancer in the same age category had diabetes. This lack of difference in rates of comorbidities between the two populations may be due to a selection bias. Healthier cancer patients likely have a survival advantage as compared to cancer patients with greater baseline comorbidities and therefore may be more similar to the non-cancer patients.

\section{Cancer in younger adults}

While overall, the risk of cancer increases with age, certain cancers are more likely to be diagnosed among younger than older individuals. For instance, bone cancer is most frequently diagnosed among those younger than 20 years of age. Neuroblastomas are more common in children than adults (152). Furthermore, there is emerging evidence showing that rates of certain cancers have disproportionally increased among younger adults aged 25-49 years (198), with the largest increase in cancers associated with obesity. A recent epidemiological study in the U.S. found that from 1995 to 2014, there was an increase in the incidence of 12 obesity-related cancers, such as multiple myeloma, colorectal, uterine, gallbladder, kidney and pancreatic cancer among young adults age 25-49 years (198). During this period, obesity prevalence in the U.S. has also increased by more than $100 \%$ among children and young adults (199). Data from other westernized countries have also reported that rates of colorectal, gastric, and endometrial tumours are rising among young adults across the world despite stable or decreasing rates of these cancers in other age groups (200205). Even more concerning, mortality rates for colorectal cancer have also increased among Caucasian individuals aged 30-39 since 1995 and for those aged 40 to 54 years since 2005 in the U.S., closely mirroring the increased incidence rates during the same period (206). In the Cancer Prevention Study II, a prospective study of over 1 million American men and women, Jacobs et al. found that every 5 unit increase in BMI was associated with a $25 \%$ higher risk of pancreatic cancer-specific mortality in individuals younger than 50 years of age (207). These findings have important clinical implications. For instance, in 2018, the American Cancer Society recommended that for those at average risk of colorectal cancer, routine screening should start at age 45 , instead of age 50 , given the significant increase in CRC among younger individuals (208). Taken together, much of the trends seen in recent years reflects increasing rates of obesity among young patients, highlighting the importance of early intervention to reduce obesity and associated cancers.

\section{Conclusions}

In summary, we have highlighted recent evidence on the relationship between obesity, diabetes, aging, and cancer. Overall, excess weight, dysregulated glycemic control, and aging increase the risk of certain cancers. The aging population, together with the epidemic of obesity and diabetes is expected to lead to unprecedented increases in cancer incidence globally. Aging, obesity, and diabetes all have a common risk factors for cancer formation such as inflammation which may be synergistic when cooccurring $(168,209)$. Patients with obesity and diabetes may also have higher rates of treatment and/or cancer related complications, which may confer a worse prognosis. Although age is one of the strongest risk factors for cancer development, there is increasing evidence to show that cancer rates have increased among younger patients, likely due to increased rates of obesity. These observations highlight the importance of early intervention to tackle obesity and to reduce rates of obesity related cancers in both older and younger individuals. Overall, these associations are complex and future studies are required to better characterize the underlying mechanisms to help inform and 
guide treatments in those with obesity, diabetes, and cancer.

\section{Acknowledgments}

Funding: None.

\section{Footnote}

Provenance and peer review: This article was commissioned by the Guest Editor (Nathan A. Berger) for the series "Energy Balance, Aging, Obesity, and Cancer" published in Translational Cancer Research. The article was sent for external peer review organized by the Guest Editor and editorial office.

Conflicts of Interest: All authors have completed the ICMJE uniform disclosure form (available at http://dx.doi. org/10.21037/tcr.2020.03.39). The series "Energy Balance, Aging, Obesity, and Cancer" was commissioned by the editorial office without any funding or sponsorship. The authors have no other conflicts of interest to declare.

Ethical Statement: The authors are accountable for all aspects of the work in ensuring that questions related to the accuracy or integrity of any part of the work are appropriately investigated and resolved.

Open Access Statement: This is an Open Access article distributed in accordance with the Creative Commons Attribution-NonCommercial-NoDerivs 4.0 International License (CC BY-NC-ND 4.0), which permits the noncommercial replication and distribution of the article with the strict proviso that no changes or edits are made and the original work is properly cited (including links to both the formal publication through the relevant DOI and the license). See: https://creativecommons.org/ licenses/by-nc-nd/4.0/.

\section{References}

1. International Comparisons: A Focus on Diabetes. CIHI 2015.

2. Ma RCW. Epidemiology of diabetes and diabetic complications in China. Diabetologia 2018;61:1249.

3. National Diabetes Statistics Report, 2017. CDC website.

4. Bhupathiraju SN, Hu FB. Epidemiology of obesity and diabetes and their cardiovascular complications. Circ Res 2016;118:1723-35.
5. Ng M, Fleming T, Robinson M, et al. Global, regional, and national prevalence of overweight and obesity in children and adults during 1980-2013: a systematic analysis for the Global Burden of Disease Study 2013. Lancet 2014;384:766-81.

6. Wang Y, Beydoun MA, Liang L, et al. Will all Americans become overweight or obese? estimating the progression and cost of the US obesity epidemic. Obesity (Silver Spring) 2008;16:2323-30.

7. NCD Risk Factor Collaboration (NCD-RisC). Worldwide trends in body-mass index, underweight, overweight, and obesity from 1975 to 2016: a pooled analysis of 2416 population-based measurement studies in 128.9 million children, adolescents, and adults. Lancet 2017;390:2627-42.

8. Dabelea D, Bell RA, D'Agostino RB, et al. Incidence of diabetes in youth in the united states. JAMA 2007;297:2716-24.

9. Skinner AC, Skelton JA. Prevalence and trends in obesity and severe obesity among children in the United States, 1999-2012. JAMA Pediatr 2014;168:561-6.

10. Harding JL, Shaw JE, Peeters A, et al. Cancer risk among people with type 1 and type 2 diabetes: disentangling true associations, detection bias, and reverse causation. Diabetes Care 2015:38:264-70.

11. Vigneri P, Frasca F, Sciacca L, et al. Diabetes and cancer. Endocr Relat Cancer 2009;16:1103-23.

12. Hense HW, Kajuter H, Wellmann J, et al. Cancer incidence in type 2 diabetes patients - first results from a feasibility study of the D2C cohort. Diabetol Metab Syndr 2011;3:15.

13. Noto H, Tsujimoto T, Sasazuki T, et al. Significantly increased risk of cancer in patients with diabetes mellitus: a systematic review and meta-analysis. Endocr Pract 2011;17:616-28.

14. Sun G, Kashyap SR. Cancer risk in type 2 diabetes mellitus: metabolic links and therapeutic considerations. J Nutr Metab 2011;2011:708183.

15. Peeters PJ, Bazelier MT, Leufkens H, et al. The risk of colorectal cancer in patients with type 2 diabetes: associations with treatment stage and obesity. Diabetes Care 2015;38:495-502.

16. Tsilidis KK, Kasimis JC, Lopez DS, et al. Type 2 diabetes and cancer: umbrella review of meta-analyses of observational studies. BMJ 2015;350:g7606.

17. van de Poll-Franse LV, Houterman S, Janssen-Heijnen $\mathrm{ML}$, et al. Less aggressive treatment and worse overall survival in cancer patients with diabetes: a large population 
based analysis. Int J Cancer 2007;120:1986-92.

18. Stein KB, Snyder CF, Barone BB, et al. Colorectal cancer outcomes, recurrence, and complications in persons with and without diabetes mellitus: a systematic review and meta-analysis. Dig Dis Sci 2010;55:1839-51.

19. Jullumstrø E, Kollind M, Lydersen S, et al. Diabetes mellitus and outcomes of colorectal cancer. Acta Oncol 2009;48:361-7.

20. Luo J, Lin HC, He K, et al. Diabetes and prognosis in older persons with colorectal cancer. Br J Cancer 2014;110:1847-54.

21. Lega IC, Austin PC, Fischer HD, et al. The impact of diabetes on breast cancer treatments and outcomes: a population-based study. Diabetes Care 2018:41:755-61.

22. Kaaks R, Kuhn T. Epidemiology: obesity and cancer-the evidence is fattening up. Nat Rev Endocrinol 2014;10:644-5.

23. Bianchini F, Kaaks R, Vainio H. Overweight, obesity, and cancer risk. Lancet Oncol 2002;3:565-74.

24. (IARC) IAfRoC. Weight Control and Physical Activity. IARC Handbooks of Cancer Prevention. Lyon: IARC Press; 2002.

25. Pollak $M$. The insulin and insulin-like growth factor receptor family in neoplasia: an update. Nat Rev Cancer 2012;12:159-69.

26. Franceschi C, Campisi J. Chronic inflammation (inflammaging) and its potential contribution to ageassociated diseases. J Gerontol A Biol Sci Med Sci 2014;69:S4-9.

27. Frasca D, Blomberg BB, Paganelli R. Aging, obesity, and inflammatory age-related diseases. Front Immunol 2017;8:1745.

28. Hong H, Wang Q, Li J, et al. Aging, Cancer and Immunity. J Cancer 2019;10:3021-7.

29. Steele CB, Thomas SK, Henley GM, et al. Vital signs: trends in incidence of cancers associated with overweight and obesity - United States, 2005-2014 MMWR Morb Mortal Wkly Rep 2017;66:1052-8.

30. Lauby-Secretan B, Scoccianti C, Loomis D, et al. Body fatness and cancer-viewpoint of the IARC working group. N Engl J Med 2016;375:794-8.

31. Islami F, Goding Sauer A, Gapstur SM, et al. Proportion of cancer cases attributable to excess body weight by US State, 2011-2015. JAMA Oncol 2019;5:384-92.

32. Rezende LFM, Arnold M, Rabacow FM, et al. The increasing burden of cancer attributable to high body mass index in Brazil. Cancer Epidemiol 2018;54:63-70.

33. Luque RM, Lopez-Sanchez LM, Villa-Osaba A, et al.
Breast cancer is associated to impaired glucose/insulin homeostasis in premenopausal obese/overweight patients. Oncotarget 2017;8:81462-74.

34. Goodwin PJ, Chlebowski RT. Obesity and cancer: insights for clinicians. J Clin Oncol 2016;34:4197-202.

35. Whitlock G, Lewington S, Sherliker P, et al. Body-mass index and cause-specific mortality in 900000 adults: collaborative analyses of 57 prospective studies. Lancet 2009;373:1083-96.

36. Arnold M, Pandeya N, Byrnes G, et al. Global burden of cancer attributable to high body-mass index in 2012: a population-based study. Lancet Oncol 2015;16:36-46.

37. Gordon-Dseagu VL, Devesa SS, Goggins M, et al. Pancreatic cancer incidence trends: evidence from the Surveillance, Epidemiology and End Results (SEER) population-based data. Int J Epidemiol 2018;47:427-39.

38. Juo YY, Gibbons MAM, Dutson E, et al. Obesity Is associated with early onset of gastrointestinal cancers in California. J Obes 2018;2018:7014073.

39. Cleary MP, Grossmann ME. Minireview: Obesity and breast cancer: the estrogen connection. Endocrinology 2009;150:2537-42.

40. World Cancer Research Fund / American Institute for Cancer Research. Food, nutrition, physical activity, and the prevention of cancer: a global perspective. Washington DC: AICR; 2007.

41. Suzuki R, Orsini N, Saji S, et al. Body weight and incidence of breast cancer defined by estrogen and progesterone receptor status--a meta-analysis. Int J Cancer 2009;124:698-712.

42. Singh P, Kapil U, Shukla N, et al. Association of overweight and obesity with breast cancer in India. Indian J Community Med 2011;36:259-62.

43. Pierobon M, Frankenfeld CL. Obesity as a risk factor for triple-negative breast cancers: a systematic review and meta-analysis. Breast Cancer Res Treat 2013;137:307-14.

44. Neuhouser ML, Aragaki AK, Prentice RL, et al. Overweight, obesity, and postmenopausal invasive breast cancer risk: a secondary analysis of the Women's Health Initiative randomized clinical trials. JAMA Oncol 2015;1:611-21.

45. Emaus MJ, van Gils CH, Bakker MF, et al. Weight change in middle adulthood and breast cancer risk in the EPICPANACEA study. Int J Cancer 2014;135:2887-99.

46. Baer HJ, Tworoger SS, Hankinson SE, et al. Body fatness at young ages and risk of breast cancer throughout life. Am J Epidemiol 2010;171:1183-94.

47. Ursin G, Paganini-Hill A, Siemiatycki J, et al. Early 
adult body weight, body mass index, and premenopausal bilateral breast cancer: data from a case-control study. Breast Cancer Res Treat 1995;33:75-82.

48. Tamimi RM, Colditz GA, Hazra A, et al. Traditional breast cancer risk factors in relation to molecular subtypes of breast cancer. Breast Cancer Res Treat 2012;131:159-67.

49. Premenopausal Breast Cancer Collaborative Group, Schoemaker MJ, Nichols HB, et al. Association of body mass index and age with subsequent breast cancer risk in premenopausal women. JAMA Oncol 2018;4:e181771.

50. Available online: http://www.aicr.org/continuous-updateproject/breast-cancer.html. Accessed February 3, 2020.

51. Renehan AG, Tyson M, Egger M, et al. Body-mass index and incidence of cancer: a systematic review and metaanalysis of prospective observational studies. Lancet 2008;371:569-78.

52. Boehm K, Sun M, Larcher A, et al. Waist circumference, waist-hip ratio, body mass index, and prostate cancer risk: results from the North-American case-control study Prostate Cancer \& Environment Study. Urol Oncol 2015;33:494.e1-7.

53. Yang L, Drake BF, Colditz GA. Obesity and other cancers. J Clin Oncol 2016;34:4231-7.

54. Aleksandrova K, Nimptsch K, Pischon T. Obesity and colorectal cancer. Front Biosci (Elite Ed) 2013;5:61-77.

55. Dalamaga $M$. Obesity, insulin resistance, adipocytokines and breast cancer: new biomarkers and attractive therapeutic targets. World J Exp Med 2013;3:34-42.

56. Aune D, Greenwood DC, Chan DS, et al. Body mass index, abdominal fatness and pancreatic cancer risk: a systematic review and non-lniear dose-response metaanalysis of prospective studies. Ann Oncol 2012;23:843-52.

57. van Kruijsdijk RC, van der Wall E, Visseren FL. Obesity and cancer: the role of dysfunctional adipose tissue. Cancer Epidemiol Biomarkers Prev 2009;18:2569-78.

58. Olefsky JM, Glass CK. Macrophages, inflammation, and insulin resistance. Annu Rev Physiol 2010;72:219-46.

59. Coussens LM, Werb Z. Inflammation and cancer. Nature 2002 Dec 19-26;420:860-7.

60. Balkwill F, Mantovani A. Inflammation and cancer: back to Virchow? Lancet 2001;357:539-45.

61. Hursting SD, Digiovanni J, Dannenberg AJ, et al. Obesity, energy balance, and cancer: new opportunities for prevention. Cancer Prev Res (Phila) 2012;5:1260-72.

62. Grossmann ME, Nkhata KJ, Mizuno NK, et al. Effects of adiponectin on breast cancer cell growth and signaling. $\mathrm{Br}$ J Cancer 2008;98:370-9.
63. Cong L, Gasser J, Zhao J, et al. Human adiponectin inhibits cell growth and induces apoptosis in human endometrial carcinoma cells, HEC-1-A and RL95 2. Endocr Relat Cancer 2007;14:713-20.

64. Kim AY, Lee YS, Kim KH, et al. Adiponectin represses colon cancer cell proliferation via AdipoR1- and -R2-mediated AMPK activation. Mol Endocrinol 2010;24:1441-52.

65. Paz-Filho G, Mastronardi C, Delibasi T, et al. Congenital leptin deficiency: diagnosis and effects of leptin replacement therapy. Arq Bras Endocrinol Metabol 2010;54:690-7.

66. Considine RV, Sinha MK, Heiman ML, et al. Serum immunoreactive-leptin concentrations in normal-weight and obese humans. N Engl J Med 1996;334:292-5.

67. Bub JD, Miyazaki T, Iwamoto Y. Adiponectin as a growth inhibitor in prostate cancer cells. Biochem Biophys Res Commun 2006;340:1158-66.

68. Gialamas SP, Sergentanis TN, Antonopoulos CN, et al. Circulating leptin levels and risk of colorectal cancer and adenoma: a case-control study and meta-analysis. Cancer Causes Control 2013;24:2129-41.

69. Newman G, Gonzalez-Perez RR. Leptin-cytokine crosstalk in breast cancer. Mol Cell Endocrinol 2014;382:570-82.

70. Gillespie C, Quarshie A, Penichet M, et al. Potential role of leptin signaling in DMBA-induced mammary tumors by non-responsive C57BL/6J mice fed a high-fat diet. J Carcinogene Mutagene 2012:3:132.

71. Travis RC, Key TJ. Oestrogen exposure and breast cancer risk. Breast Cancer Res 2003;5:239-47.

72. Péqueux C, Raymond-Letron I, Blacher S, et al. Stromal estrogen receptor- $\alpha$ promotes tumor growth by normalizing an increased angiogenesis. Cancer Res 2012;72:3010-9.

73. Key TJ, Appleby PN, Reeves GK et al. Body mass index, serum sex hormones, and breast cancer risk in postmenopausal women. J Natl Cancer Inst 2003;95:1218-26.

74. López-Suárez A. Burden of cancer attributable to obesity, type 2 diabetes and associated risk factors. Metabolism 2019;92:136-46.

75. Meyerhardt JA, Tepper JE, Niedzwiecki D, et al. Impact of body mass index on outcomes and treatment-related toxicity in patients with stage II and III rectal cancer: findings from Intergroup Trial 0114. J Clin Oncol 2004;22:648-57.

76. Jiralerspong S, Goodwin PJ. Obesity and breast cancer prognosis: evidence, challenges, and opportunities. J Clin 
Oncol 2016;34:4203-16.

77. Fleming JB, Gonzalez RJ, Petzel MQ, et al. Influence of obesity on cancer-related outcomes after pancreatectomy to treat pancreatic adenocarcinoma. Arch Surg 2009; 144:216-21.

78. Yuan C, Bao Y, Wu C, et al. Prediagnostic body mass index and pancreatic cancer survival. J Clin Oncol 2013;31:4229-34.

79. Dignam JJ, Polite BN, Yothers G, et al. Body mass index and outcomes in patients who receive adjuvant chemotherapy for colon cancer. J Natl Cancer Inst 2006;98:1647-54.

80. Sinicrope FA, Foster NR, Sargent DJ, et al. Obesity is an independent prognostic variable in colon cancer survivors. Clin Cancer Res 2010;16:1884-93.

81. Goodwin PJ. Obesity and breast cancer outcomes: How much evidence is needed to change practice? J Clin Oncol 2016;34:646-8.

82. Chan DS, Vieira AR, Aune D, et al: Body mass index and survival in women with breast cancer: Systematic literature review and meta-analysis of 82 follow-up studies. Ann Oncol 2014;25:1901-14.

83. Majed B, Moreau T, Senouci K, et al. Is obesity an independent prognosis factor in woman breast cancer? Breast Cancer Res Treat 2008;111:329-42.

84. Ewertz M, Jensen MB, Gunnarsdóttir KA, et al. Effect of obesity on prognosis after early-stage breast cancer. J Clin Oncol 2011;29:25-31.

85. Wee CC, McCarthy EP, Davis RB et al. Obesity and breast cancer screening. J Gen Intern Med.2004;19:324-31.

86. Kerlikowske K, Grady D, Rubin SM, et al. Efficacy of screening mammography. A meta-analysis. JAMA 1995;273:149-54.

87. Hum S, Wu M, Pruthi S, et al. Physician and patient barriers to breast cancer preventive therapy. Curr Breast Cancer Rep 2016;8:158-64.

88. Cespedes Feliciano EM, Kwan ML, Kushi LH, et al. Body mass index, PAM50 subtype, recurrence, and survival among patients with nonmetastatic breast cancer. Cancer 2017;123:2535-42.

89. Jeon, YW, Kang SH, Park MH, et al. Relationship between body mass index and the expression of hormone receptors or human epidermal growth factor receptor 2 with respect to breast cancer survival. BMC Cancer 2015;15:865.

90. Blair CK, Wiggins CL, Nibbe AM, et al. Obesity and survival among a cohort of breast cancer patients is partially mediated by tumour characteristics. NPJ Breast Cancer 2019;5:33.
91. Early Breast Cancer Trialists' Collaborative Group (EBCTCG), Darby S, McGale P, et al. Effect of radiotherapy after breast-conserving surgery on 10year recurrence and 15-year breast cancer death: metaanalysis of individual patient data for 10,801 women in 17 randomised trials. Lancet 2011;378:1707-16.

92. Wang T, Fahrmann JF, Lee H, et al. JAK/STAT3regulated fatty acid beta-oxidation is critical for breast cancer stem cell self-renewal and chemoresistance. Cell Metab 2018;27:136-150.e5.

93. Pandit JJ, Andrade J, Bogod DG, et al. 5th National Audit Project (NAP5) on accidental awareness during general anaesthesia: summary of main findings and risk factors. $\mathrm{Br}$ J Anaesth 2014;113:549-59.

94. Iyigun ZE, Duymaz T, Ilgun AS, et al. Preoperative lymphedema-related risk factors in early-stage breast cancer. Lymphat Res Biol 2018;16:28-35.

95. Paskett ED, Dean JA, Oliveri JM, et al. Cancer-related lymphedema risk factors, diagnosis, treatment, and impact: a review. J Clin Oncol 2012;30:3726-33.

96. Gacci M, Sebastianelli A, Salvi M, et al. Role of abdominal obesity for functional outcomes and complications in men treated with radical prostatectomy for prostate cancer: results of the Multicenter Italian Report on Radical Prostatectomy (MIRROR) study. Scand J Urol 2014;48:138-45.

97. Poelemeijer YQM, Lijftogt N, Determing R, et al. Obesity as a determinant of perioperative and postoperative outcome in patients following colorectal cancer surgery: A population-based study (2009-2016). Eur J Surg Oncol 2018;44:1849-57.

98. Parker ED, Folsom AR. Intentional weight loss and incidence of obesity-related cancers: the Iowa Women's Health Study. Int J Obes Relat Metab Disord 2003;27:1447-52.

99. Luo J, Chlebowski RT, Hendryx M, et al. Intentional Weight Loss and Endometrial Cancer Risk. J Clin Oncol 2017;35:1189-93.

100.Luo J, Hendryx M, Manson JE, et al. Intentional weight loss and obesity-related cancer risk. JNCI Cancer Spectr 2019;3:pkz054.

101. Schauer DP, Feigelson HS, Koebnick C, et al. Bariatric surgery and the risk of cancer in a large multisite cohort. Ann Surg 2019;269:95-101.

102. Grosso G, Bella F, Godos J, et al. Possible role of diet in cancer: systematic review and multiple meta-analyses of dietary patterns, lifestyle factors, and cancer risk. Nutr Rev 2017;75:405-19. 
103. Katzke VA, Kaaks R, Kuhn T. Lifestyle and cancer risk. Cancer J 2015;21:104-10.

104. Chlebowski RT, Blackburn GL, Thomson CA, et al. Dietary fat reduction and breast cancer outcome: interim efficacy results from the Women's Intervention Nutrition Study. J Natl cancer Inst 2006;98:1767-76.

105.Chlebowski R, Blackburn G, Hoy M, et al. Survival analyses from the Women's Intervention Nutrition Study (WINS) evaluating dietary fat reduction and breast cancer outcome. Paper presented at: American Society of Clinical Oncology Annual Meeting; May 30June 3, 2008; Chicago, IL.

106.Janni W, Rack BK, Friedl TW, et al. Lifestyle intervention and effect on disease-free survival in early breast cancer pts: interim analysis from the randomized SUCCESS C study. Cancer Res 2019;79:suppl;abstr GS5-03.

107. Medical College of Wisconsin. Every Day Counts: A Lifestyle Program for Women With Metastatic Breast Cancer (EDC). Available online: https://clinicaltrials.gov/ ct2/show/NCT03824145. Accessed February 3, 2020.

108. Luo S, Li JY, Zhao LN, et al. Diabetes mellitus increases the risk of colorectal neoplasia: An updated meta-analysis. Clin Res Hepatol Gastroenterol 2016;40:110-23.

109.Jing W, Jin G, Zhou X, et al. Diabetes mellitus and increased risk of cholangiocarcinoma: a meta-analysis. Eur J Cancer Prev 2012;21:24-31.

110.Liao S, Li J, Wei W, et al. Association between diabetes mellitus and breast cancer risk: a meta-analysis of the literature. Asian Pac J Cancer Prev 2011;12:1061-5.

111.Huxley R, Ansary-Moghaddam A, Berrington de Gonzalez A, et al. Type-II diabetes and pancreatic cancer: a metaanalysis of 36 studies. Br J Cancer 2005;92:2076-83.

112. Renehan AG, Yeh HC, Johnson JA, et al. Diabetes and cancer (2): evaluating the impact of diabetes on mortality in patients with cancer. Diabetologia 2012;55:1619-32.

113.Johnson JA, Carstensen B, Witte D, et al. Diabetes and cancer (1): evaluating the temporal relationship between type 2 diabetes and cancer incidence. Diabetologia 2012;55:1607-18.

114. de Jong RG, Burden AM, de Kort S, et al. Impact of detection bias on the risk of gastrointestinal cancer and its subsites in type 2 diabetes mellitus. Eur J Cancer 2017;79:61-71.

115. Onitilo AA, Stankowski RV, Berg RL, et al. Breast cancer incidence before and after diagnosis of type 2 diabetes mellitus in women: increased risk in the prediabetes phase. Eur J Cancer Prev 2014;23:76-83.

116.Lega IC, Wilton AS, Austin PC, et al. The temporal relationship between diabetes and cancer: A populationbased study. Cancer 2016;122:2731-8.

117. Bansal D, Bhansali A, Kapil G, et al. Type 2 diabetes and risk of prostate cancer: a meta-analysis of observational studies. Prostate Cancer Prostatic Dis 2013;16:151-8, S1.

118. Kasper JS, Giovannucci E. A meta-analysis of diabetes mellitus and the risk of prostate cancer. Cancer Epidemiol Biomarkers Prev 2006;15:2056-62.

119. Dhindsa S, Prabhakar S, Sethi M, et al. Frequent occurrence of hypogonadotropic hypogonadism in type 2 diabetes. J Clin Endocrinol Metab 2004;89:5462-8.

120. Beckmann K, Crawley D, Nordstrom T, et al. Association between anti-diabetic medications and prostate-specific antigen levels and biopsy results. JAMA Netw Open 2019;2:e1914689.

121.Hankinson SJ, Fam M, Patel NN. A review for clinicians: prostate cancer and the antineoplastic properties of metformin. Urol Oncol 2017;35:21-9.

122.Lucenteforte E, Bosetti C, Talamini R, et al. Diabetes and endometrial cancer: effect modification by body weight, physical activity and hypertension. Br J Cancer 2007;97:995-8.

123. Pearson-Stuttard J, Zhou B, Kontis V, et al. Worldwide burden of cancer attributable to diabetes and high bodymass index: a comparative risk assessment. Lancet Diabetes Endocrinol 2018;6:e6-15.

124. Carstensen B, Read SH, Friis S, et al. Cancer incidence in persons with type 1 diabetes: a five-country study of 9,000 cancers in type 1 diabetic individuals. Diabetologia 2016;59:980-8.

125. Sona MF, Myung SK, Park K, et al. Type 1 diabetes mellitus and risk of cancer: a meta-analysis of observational studies. Jpn J Clin Oncol 2018;48:426-33.

126. Kahn SE. The relative contributions of insulin resistance and beta-cell dysfunction to the pathophysiology of type 2 diabetes. Diabetologia 2003;46:3-19.

127.Færch K, Witte DR, Tabak AG, et al. Trajectories of cardiometabolic risk factors before diagnosis of three subtypes of type 2 diabetes: a post-hoc analysis of the longitudinal Whitehall II cohort study. Lancet Diabetes Endocrinol 2013;1:43-51.

128. Gallagher EJ, LeRoith D. The proliferating role of insulin and insulin-like growth factors in cancer. Trends Endocrinol Metab 2010;21:610-8.

129.Pisani P. Hyper-insulinaemia and cancer, meta-analyses of epidemiological studies. Arch Physiol Biochem 2008;114:63-70.

130. Rabiau N, Dechelotte P, Adjakly M, et al. BRCA1, 
BRCA2, AR and IGF-I expression in prostate cancer: correlation between RT-qPCR and immunohistochemical detection. Oncology Reports 2011;26:695-702.

131. Stubbs MC, Kim YM, Krivtsov AV, et al. MLL-AF9 and FLT3 cooperation in acute myelogenous leukemia: development of a model for rapid therapeutic assessment. Leukemia 2008;22:66-77.

132.Jenkins CR, Shevchuk OO, Giambra V, et al. IGF signaling contributes to malignant transformation of hematopoietic progenitors by the MLL-AF9 oncoprotein. Exp Hematol 2012;40:715-723.e6.

133. Djiogue S, Nwabo Kamdje AH, Vecchio L, et al. Insulin resistance and cancer: the role of insulin and IGFs. Endocr Relat Cancer 2013;20:R1-17.

134. Sanchez-Lopez E, Flashner-abramson E, Shalapour S, et al. Targeting colorectal cancer via its microenvironemnt by inihibiting IGF-1 receptor-insulin receptor substrate and STAT3 signaling. Oncogene 2016;35:2634-44.

135.Al-Delaimy WK, Flatt SW, Natarajan L, et al. IGF1 and risk of additional breast cancer in the WHEL study. Endocr Relat Cancer 2011;18:235-44.

136. Novosyadlyy R, Lann DE, Vijayakumar A, et al. Insulinmediated acceleration of breast cancer development and progression in a nonobese model of type 2 diabetes. Cancer Res 2010;70:741-51.

137.Lu CC, Chu PY, Hsia SM, et al. Insulin induction instigates cell proliferation and metastasis in human colorectal cancer cells. Int J Oncol 2017;50:736-44.

138. Warburg O. On the origin of cancer cells. Science 1956;123:309-14.

139. Vander Heiden MG, Cantley LC, Thompson CB. Understanding the Warburg effect: the metabolic requirements of cell proliferation. Science 2009;324:1029-33.

140.Leclerc E, Vetter SW. The role of S100 proteins and their receptor RAGE in pancreatic cancer. Biochim Biophys Acta 2015;1852:2706-11.

141.Xu J, Ye Y, Wu H, et al. Association between markers of glucose metabolism and risk of colorectal cancer. BMJ Open 2016;6:e011430.

142.Dankner R, Boker LK, Boffetta P, et al. A historical cohort study on glycemic-control and cancer-risk among patients with diabetes. Cancer Epidemiol 2018;57:104-9.

143. Qiang JK, Sutradhar R, Giannakeas V, et al. Impact of diabetes on colorectal cancer stage and mortality risk: a population-based cohort study. Diabetologia 2020. [Epub ahead of print].

144.El Brahimi S, Smith ML, Pinheiro PS. Role of pre-existing type 2 diabetes in colorectal cancer survival among older Americans: a SEER-Medicare population-based study 2002-2011. Int J Colorectal Dis 2019;34:1467-75.

145. Rao Kondapally Seshasai S, Kaptoge S, Thompson A, et al. Diabetes mellitus, fasting glucose, and risk of causespecific death. N Engl J Med 2011;364:829-41.

146. Peairs KS, Barone BB, Snyder CF, et al. Diabetes mellitus and breast cancer outcomes: a systematic review and metaanalysis. J Clin Oncol 2011;29:40-6.

147.Zhu B, Wu XM, Wu B, et al. The relationship between diabetes and colorectal cancer prognosis: A meta-analysis based on the cohort studies. PLoS One 2017;12:e0176068.

148. Barone BB, Yeh HC, Snyder CF, et al. Long-term allcause mortality in cancer patients with preexisting diabetes mellitus: a systematic review and meta-analysis. JAMA 2008;300:2754-64.

149. Worndl E, Fung K, Fischer HD, et al. Preventable diabetic complications after a cancer diagnosis in patients with diabetes: a population-based cohort study. JNCI Cancer Spectr 2018;2:pky008.

150.Xu G, Liu B, Sun Y, et al. Prevalence of diagnosed type 1 and type 2 diabetes among US adults in 2016 and 2017: population based study. BMJ 2018;362:k1497.

151.Available online: https://www.cdc.gov/diabetes/pdfs/data/ statistics/national-diabetes-statistics-report.pdf. Accessed February 3, 2020.

152.Age and cancer risk. (2015, April 29). Retrieved January 4, 2020, Available online: https://www.cancer.gov/aboutcancer/causes-prevention/risk/age

153. Available online: https://progressreport.cancer.gov/ diagnosis/incidence. Accessed February 3, 2020.

154. Available online: https://www.cancer.ca/en/about-us/formedia/media-releases/national/2015/canadian-cancerstatistics-2015/?region=on. Accessed February 3, 2020.

155. Available online: https://www150.statcan.gc.ca/n1/pub/11402-x/2010000/chap/pop/c-g/desc/desc04-eng.htm. Accessed February 3, 2020.

156.Available online: https://www.cancer.ca/ /media/ cancer.ca/CW/cancer\%20information/cancer\%20101/ Canadian\%20cancer\%20statistics/Canadian-CancerStatistics-2019-EN.pdf?la=en. Accessed February 3, 2020.

157. Collerton J, Martin-Ruiz C, Davies K, et al. Frailty and the role of inflammation, immunosenescence and cellular ageing in the very old: cross-sectional findings from the Newcastle 85+ Study. Mech Ageing Dev 2012;133:456-66.

158. Akiyama M, Kyoizumi S, Hirai Y, et al. Mutation frequency in human blood cells increases with age. Mutat Res 1995;338:141-9. 
159. Ramsey MJ, Moore DH, Briner JF, et al. The effects of age and lifestyle factors on the accumulation of cytogenetic damage as measured by chromosome painting. Mutat Res 1995;338:95-106.

160.Jacobs KB, Yeager M, Zhou W, et al. Detectable clonal mosaicism and its relationship to aging and cancer. Nat Genet 2012;44:651-8.

161.Laurie CC, Laurie CA, Rice K, et al. Detectable clonal mosaicism from birth to old age and its relationship to cancer. Nat Genet 2012;44:642-50.

162.Forsberg LA, Rasi C, Razzaghian HR, et al. Age-related somatic structural changes in the nuclear genome of human blood cells. Am J Hum Genet 2012;90:217-28.

163. Nair N, Camacho-Vanegas O, Rykunov D, et al. Genomic analysis of uterine lavage fluid detects early endometrial cancers and reveals a prevalent landscape of driver mutations in women without histopathologic evidence of cancer: A prospective cross-sectional study. PLoS Med 2016;13:e1002206-26.

164. Forsberg LA, Rasi C, Malmqvist N, et al. Mosaic loss of chromosome $\mathrm{Y}$ in peripheral blood is associated with shorter survival and higher risk of cancer. Nat Genet 2014;46:624-8.

165.Agopian J, Navarro JM, Gac AC, et al. Agricultural pesticide exposure and the molecular connection to lymphomagenesis. J Exp Med 2009;206:1473-83.

166. Hearps AC, Martin GE, Angelovich TA, et al. Aging is associated with chronic innate immune activation and dysregulation of monocyte phenotype and function. Aging Cell 2012;11:867-75.

167.Jing Y, Shaheen E, Drake RR, et al. Aging is associated with a numerical and functional decline in plasmacytoid dendritic cells, whereas myeloid dendritic cells are relatively unaltered in human peripheral blood. Hum Immunol 2009;70:777-84.

168.Zhang X, Meng X, Chen Y, et al. The biology of aging and cancer: frailty, inflammation, and immunity. Cancer J 2017;23:201-5.

169. Mantovani A, Marchesi F, Malesci A, et al. Tumour associated macrophages as treatment targets in oncology. Nat Rev Clin Oncol 2017;14:399-416.

170.Zhang WJ, Wang XH, Gao ST, et al. Tumour-associated macrophages correlate with phenomenon of epithelialmesenchymal transition and contribute to poor prognosis in triple-negative breast cancer patients. J Surg Res 2018;222:93-101.

171.Steidl C, Lee T, Shah SP, et al. Tumour-associated macrophages and survival in classic Hodgkin's lymphoma.
N Engl J Med 2010;362:875-85.

172.Malesci A, Bianchi P, Celesti G, et al. Tumour-associated macrophages and response to 5-fluorouracil adjuvant therapy in stage III colorectal cancer. Oncoimmunology 2017;6:e1342918.

173. Quaresma M, Coleman MP, Rachet B. 40-year trends in an index of survival for all cancers combined and survival adjusted for age and sex for each cancer in England and Wales, 1971-2011: a population-based study. Lancet 2015;385:1206-18.

174. DeSantis CE, Miller KD, Dale W, et al. Cancer statistics for adults aged 85 years and older, 2019. CA Cancer J Clin 2019;69:452-67.

175.LeMasters T, Madhavan SS, Sambamoorthi U, et al. Receipt of guideline-concordant care among older women with stage I-III breast cancer: a population-based study. J Natl Compr Canc Netw 2018;16:703-10.

176. Giordano SH, Hortobagyi GN, Kau SW, et al. Breast cancer treatment guidelines in older women. J Clin Oncol 2005;23:783-91.

177. de la Morena Barrio P, Conesa MÁ, González-Billalabeitia E. Delayed recovery and increased severity of paclitaxelinduced peripheral neuropathy in patients with diabetes. J Natl Compr Canc Netw 2015;13:417-23.

178. Swaminathan D, Swaminathan V. Geriatric oncology: problems with under-treatment within this population. Cancer Biol Med 2015;12:275-83.

179. Hurria A, Jones L, Muss HB. Cancer treatment as an accelerated aging process: assessment, biomarkers, and interventions. Am Soc Clin Oncol Educ Book 2016;35:e516-22.

180. Gold HT, Makarem N, Nicholson JM, et al. Treatment and outcomes in diabetic breast cancer patients. Breast Cancer Res Treat 2014;143:551-70.

181.Hurria A, Levit LA, Dale W, et al. Improving the evidence base for treating older adults with cancer: american society of clinical oncology statement. J Clin Oncol 2015;33:3826-33.

182.Abdul-Aziz AM, Sun Y, Marleni CR, et al. Acute myeloid leukemia induces protumoral p16INK4a-driven senescence in the bone marrow microenvironment. Blood 2019;133:446-56.

183.López-Otín C, Blasco MA, Partridge L, et al. The hallmarks of aging. Cell 2013;153:1194-217.

184. Kim JH, Jenrow KA, Brown SL. Mechanisms of radiationinduced normal tissue toxicity and implications for future clinical trials. Radiat Oncol J 2014;32:103-15.

185. Campisi J. Aging, cellular senescence, and cancer. Annu 
Rev Physiol 2013;75:685-705.

186. Chang BD, Swift ME, Shen M, et al. Molecular determinants of terminal growth arrest induced in tumour cells by a chemotherapeutic agent. Proc Natl Acad Sci U S A 2002; 99:389.

187. Sanoff HK, Deal AM, Krishnamurthy J, et al. Effect of cytotoxic chemotherapy on markers of molecular age in patients with breast cancer. J Natl Cancer Inst 2014;106:dju057.

188. Buttiglieri S, Ruella M, Risso A, et al. The aging effect of chemotherapy on cultured human mesenchymal stem cells. Exp Hematol 2011;39:1171-81.

189. Diker-Cohen T, Uziel O, Szyper-Kravitz M, et al. The effect of chemotherapy on telomere dynamics: clinical results and possible mechanisms. Leuk Lymphoma 2013;54:2023-9.

190. Cupit-Link MC, Kirkland JL, Ness KK, et al. Biology of premature ageing in survivors of cancer. ESMO Open 2017;2:e000250.

191.Armenian SH, Gibson CJ, Rockne RC, et al. Premature aging in young cancer survivors. J Natl Cancer Inst 2019;111:226-32.

192. Henderson TO, Ness KK, Cohen HJ. Accelerated aging among cancer survivors: from pediatrics to geriatrics. Am Soc Clin Oncol Educ Book 2014;e423-30.

193. Ness KK, Armstrong GT, Kundu M, et al. Frailty in childhood cancer survivors. Cancer 2015;121:1540-7.

194. Oeffinger KC, Mertens AC, Sklar CA, et al. Chronic health conditions in adult survivors of childhood cancer. N Engl J Med 2006;355:1572-82.

195. Bhakta N, Liu Q, Ness KK. The cumulative burden of surviving childhood cancer: an initial report from the St Jude Lifetime Cohort Study (SJLIFE). Lancet 2017;390:2569-82.

196. Gibson TM, Mostoufi-Moab S, Stratton KL, et al. Temporal patterns in the risk of chronic health conditions in survivors of childhood cancer diagnosed 1970-99: a report from the Childhood Cancer Survivor Study cohort. Lancet Oncol 2018;19:1590-601.

197. Bluethmann SM, Mariotto AG, Rowland JH. Anticipating the 'silver tsunami': prevalence trajectories and comorbidity burden among older cancer survivors in the United States. Cancer Epidemiol Biomarkers Prev 2016;25:1029-36.

198. Sung H, Siegel RL, Rosenberg PS, et al. Emerging cancer trends among young adults in the USA: analysis of a population-based cancer registry. Lancet Public Health 2019;4:e137-47
199. Centers for Disease Control and Prevention Prevalence of overweight, obesity, and extreme obesity among adults aged 20 and over: United States, 1960-1962 through 20132014. Available online: https://www.cdcgov.myaccess. library.utoronto.ca/nchs/data/hestat/obesity_adult_13_14/ obesity_adult_13_14.htm. Accessed Dec 142019.

200. Brenner DR, Heer E, Sutherland RL, et al. National Trends in Colorectal Cancer Incidence Among Older and Younger Adults in Canada. JAMA Netw Open 2019;2:e198090.

201. Siegel RL, Fedewa SA, Anderson WF, et al. Colorectal cancer incidence patterns in the United States, 1974-2013. J Natl Cancer Inst 2017. doi: 10.1093/jnci/djw322.

202.Araghi M, Soerjomataram I, Bardot A, et al. Changes in colorectal cancer incidence in seven high-income countries: a population-based study. Lancet Gastroenterol Hepatol 2019;4:511-8.

203. Russo AG, Andreano A, Sartore-Bianchi A, et al. Increased incidence of colon cancer among individuals younger than 50 years: a 17 years analysis from the cancer registry of the municipality of Milan, Italy. Cancer Epidemiol 2019;60:134-40.

204. Wang Z, Graham DY, Khan A, et al. Incidence of gastric cancer in the USA during 1999 to 2013: a 50-state analysis. Int J Epidemiol 2018;47:966-75.

205. Moore K, Brewer MA. Endometrial Cancer: is this a new disease? Am Soc Clin Oncol Educ Book 2017;37:435-42.

206. Siegel RL, Miller KD, Jemal A. Colorectal cancer mortality rates in adults aged 20 to 54 years in the United States, 1970-2014. JAMA 2017;318:572-4.

207.Jacobs EJ, Newton CC, Patel AV, et al. The association of body mass index with pancreatic cancer: variation by age at body mass index assessment. Am J Epidemiol 2020;189:108-15.

208. Wolf AMD, Fontham ETH, Church TR et al. Colorectal cancer screening for average-risk adults: 2018 guideline update from the American Cancer Society. CA Cancer J Clin 2018;68:250-81.

209. Burton DGA, Faragher RGA. Obesity and type-2 diabetes as inducers of premature cellular senescence and ageing. Biogerontology 2018;19:447-59.

Cite this article as: Qiang JK, Lipscombe LL, Lega IC. Association between diabetes, obesity, aging, and cancer: review of recent literature. Transl Cancer Res 2020;9(9):5743-5759. doi: 10.21037/tcr.2020.03.14 